\title{
Morphologic study of the cornea by in vivo confocal microscopy and optical coherence tomography after bifocal refractive corneal inlay implantation
}

\author{
Alex Malandrini, MD, PhD, Gianluca Martone, MD, PhD, Annalisa Canovetti, MD, \\ Luca Menabuoni, MD, Angelo Balestrazzi, MD, PhD, Chiara Fantozzi, Chiara Lenzetti, \\ Marco Fantozzi, MD
}

\begin{abstract}
PURPOSE: To evaluate the biocompatibility of the Flexivue Microlens intracorneal inlay based on healing of corneal wounds and analysis of corneal structural features using in vivo confocal microscopy (IVCM) and anterior segment optical coherence tomography (AS-OCT).
\end{abstract}

SETTING: Ophthalmology Department, Misericordia e Dolce Hospital, Prato, Italy.

DESIGN: Case series.

METHODS: The intracorneal inlay was inserted in a stromal pocket created in the nondominant eye of emmetropic presbyopic patients using a femtosecond laser. In vivo confocal microscopy and AS-OCT examinations were performed preoperatively and 1, 6, and 12 months postoperatively.

RESULTS: The mean follow-up was 7.6 months. In the early postoperative period, IVCM showed intense cellular activity in the stroma around the inlay, edema, inflammation, and degenerative material deposition but normal regularity after 12 months. Anterior segment OCT showed a regular planar shape of the corneal pocket in all eyes. The mean of the side-cut angles was 30.7 degrees. The mean difference between the measured and planned pocket depth was $9.77 \mu \mathrm{m}$. At 1 month, hyperreflective areas beneath the inlay and microfolds were observed in 21 of the 52 eyes. After 12 months, the anterior segment profile was regular and interface pocket reflectivity decreased over time. Six patients had inlay removal postoperatively (3 before 6 months; 3 before 12 months); after removal, IVCM and AS-OCT showed clear corneas without signs of irregularity.

CONCLUSION: In vivo confocal microscopy and AS-OCT analysis showed that the inlay elicited a low-level wound-healing response in its immediate vicinity with no alteration in the corneal structures.

Financial Disclosure: Dr. M. Fantozzi is a member of the Presbia medical advisory board. No other author has a financial or proprietary interest in any material or method mentioned.

J Cataract Refract Surg 2014; 40:545-557 @ 2014 ASCRS and ESCRS

With an ever-growing population of patients older than 45 years, the number of reported cases of age-related conditions, such as presbyopia, continues to increase annually. Corneal procedures for the treatment of presbyopia include presbyopic laser in situ keratomileusis (LASIK), conductive keratoplasty, intracorneal implants (or inlays), ${ }^{1-3}$ and Intracor ${ }^{4}$ and Supracor laser procedures (Technolas, Bausch \& Lomb ${ }^{\mathrm{A}}$ ).

Recent advances in femtosecond laser and material technologies and a growing demand by informed patients for a removable treatment option for presbyopia are contributing factors to a renewed interest in intracorneal inlay options. The Flexivue Microlens intracorneal inlay (Presbia Coöperatief U.A.) was designed to improve the near focus in the nondominant eye through the bifocal-optic lenticule design. ${ }^{\mathrm{B}}$

To examine the biocompatibility of the intracorneal inlay, we used 2 anterior segment diagnostic tools to identify changes after inlay insertion in the cornea: in vivo confocal microscopy (IVCM) and anterior segment optical coherence tomography (AS-OCT). Both diagnostic tools are useful for ocular surface 
imaging. ${ }^{5-8}$ In vivo confocal microscopy is an important noninvasive instrument that can be used to detect histologic changes by providing morphologic and quantitative data associated with the corneal layers. ${ }^{9}$ Anterior segment OCT is another tool for the evaluation of corneal and anterior chamber structures; it is useful because it shows corneal thickness, flap or pocket morphology and thickness, and the progressive healing of the cornea. ${ }^{10}$ To date, we are aware of only 1 published study that used these 2 tools to evaluate the postoperative outcomes in eyes that had insertion of the Flexivue Microlens. ${ }^{11}$

In this study of patients treated with the Flexivue Microlens intracorneal inlay, we present the results of the use of IVCM to evaluate biocompatibility and corneal wound healing and AS-OCT to measure corneal and pocket thickness.

\section{PATIENTS AND METHODS}

This morphologic case series study was designed as a 1-year prospective nonrandomized noncomparative study to evaluate the biocompatibility of the Flexivue Microlens intracorneal inlay in emmetropic presbyopic patients. Surgeries were performed at the Ophthalmology Department, Misericordia e Dolce Hospital, Prato, Italy. The study was performed in accordance with the Declaration of Helsinki and approved by the hospital's ethics committee. All patients provided signed informed consent for participation in the study after receiving a detailed explanation of the purpose, procedure, and patient responsibilities.

Patients were eligible for inclusion in the study if they were naturally emmetropic and presbyopic, between 45 years and 65 years of age, and had a preoperative refractive spherical equivalent (SE) power between $-1.0 \mathrm{D}$ and $+1.0 \mathrm{D}$ with no more than $+1.0 \mathrm{D}$ of refractive cylinder. Patients were required to have a preoperative uncorrected near visual acuity of 20/50 or worse in the surgical eye and uncorrected distance visual acuity (UDVA) of 20/32 or better in both eyes with no amblyopia. Additional key inclusion criteria included a minimum central corneal thickness (CCT) of $500 \mu \mathrm{m}$ and an endothelial cell density (ECD) of 2000 cells $/ \mathrm{mm}^{2}$ in the surgical eye. All patients were required to

Submitted: December 19, 2012.

Final revision submitted: August 24, 2013.

Accepted: August 27, 2013.

From the Department of Ophthalmology (Malandrini, Canovetti, Menabuoni, C. Fantozzi, M. Fantozzi, Lenzetti), Misericordia e Dolce Hospital, Prato, and the Department of Ophthalmology (Martone, Balestrazzi), University of Siena, Siena, Italy.

Anna Maria Catanese, MD, PhD, Department of Ophthalmology, Misericordia e Dolce Hospital, Prato, Italy, assisted with the clinical investigations.

Corresponding author: Alex Malandrini, MD, PhD, Department of Ophthalmology, Misericordia e Dolce Hospital, viale Cavour number 1, 59100 Prato, Italy. E-mail: alexmalandrini@libero.it. have a stable refraction (manifest refraction within $\pm 0.50 \mathrm{D}$ sphere) 12 months before surgery.

Key exclusion criteria were previous ocular surgery, anterior or posterior segment disease or degeneration, and a disorder or systemic medication (eg, use of steroids, medications for diabetes) that could increase operative risks and interfere with the ordinary healing process. In addition, patients with distorted nonreactive or decentered pupils, a photopic pupil diameter smaller than $3.0 \mathrm{~mm}$, severe dry eye (Schirmer test $<3.0 \mathrm{~mm}$ ), or severe corneal abnormalities (eg, endothelial dystrophy, guttata in the central cornea) in the eye to be treated were excluded from the study.

\section{Intracorneal Inlay}

The Flexivue Microlens is a transparent hydrophilic disk with a $3.0 \mathrm{~mm}$ diameter and an edge thickness of approximately $15 \mu \mathrm{m}$. The central $1.6 \mathrm{~mm}$ diameter of the disk is plano, while the peripheral zone provides near addition power. The base powers available range from +1.50 diopters (D) to $+3.50 \mathrm{D}$ in $0.25 \mathrm{D}$ increments. At the center of the disk is a $0.51 \mathrm{~mm}$ hole for the transfer of oxygen and nutrients to the cornea.

\section{Surgical Technique}

All surgeries were performed by the same experienced surgeon (M.F.) between January 2010 and July 2012. One day before surgery, patients were instructed to start topical levofloxacin (Oftaquix) treatment in combination with topical tobramycin-dexamethasone (Tobradex) drops 4 times daily. Ten minutes before surgery, topical flurbiprofen (Ocufen) and topical lidocaine $4.0 \%$ were administered in the operated eye; these medications could be repeated as needed during the procedure. The lids and ocular adnexa of patients were cleaned with povidone-iodine. A sterile drape was used to isolate the lid margin. A lid speculum was used to provide maximum corneal exposure, and the fornices were irrigated with a balanced salt solution.

The corneas of the patients were marked with a $3.0 \mathrm{~mm}$ ring epithelial marker (Thornton Optic Zone Marker, American Surgical Instruments Corp.) using the first Purkinje reflex corresponding to applicable visual axes without damaging the epithelium. Centration was established using an excimer laser; that is, patients fixated on the microscope light, and the center of the visual axes of patients was marked to obtain optimum centration for insertion of the intracorneal inlay. The pocket was created using standard femtosecond laser parameters (Table 1) associated with traditional LASIK in conjunction with a mask that was used to create a pocket to facilitate inlay implantation without affecting the rest of the cornea. After corneal pocket creation, patients were situated under the operating microscope for intracorneal inlay insertion. The pocket was separated using a manipulator (oval spatula part \#6-870, Duckworth \& Kent Ltd. or Storz Ophthalmics; part \#SP7-62541, Bausch \& Lomb) until it reached approximately 1.6 to $2.0 \mathrm{~mm}$ nasal to the marked center of the cornea.

After pocket preparation was complete, the intracorneal inlay was removed from the sterile packaging with a forceps, inspected for integrity under high magnification, and loaded in the inserter (Flexivue Microlens Inserter, Presbia Coöperatief U.A.). The inserter holds the lens between 2 leaves, keeping the lens protected and in place for insertion in the corneal pocket. When ready to insert the inlay, the 
Table 1. Laser parameters for femtosecond laser-assisted corneal pocket creation using a mask.

\begin{tabular}{lc}
\hline Parameter & Value \\
\hline Treatment type & iFlap \\
Method & Raster \\
Hinge & Opposite of tunnel \\
Diameter $(\mathrm{mm})$ & 9.0 to 9.5 \\
Spot separation $(\mu \mathrm{m})$ & 2.2 \\
Line separation $(\mu \mathrm{m})$ & 2.2 \\
Bed energy $(\mu \mathrm{J})$ & 0.65 \\
Depth $(\mu \mathrm{m})$ & 300 \\
Side-cut energy $(\mu \mathrm{J})$ & 1.60 to 1.70 \\
Side-cut angle $(\mu \mathrm{J})$ & 30 \\
Pocket & Deactivated \\
\hline
\end{tabular}

surgeon moved the plunger forward, properly centering the lens in the pocket based on the marked area on the cornea.

After insertion, the surgeon verified that the intracorneal inlay was properly centered in the pocket. If there was a need for recentration, the inlay was moved in the pocket by massaging the surface of the cornea with a fine blunt spatula or cannula or by manipulating the inlay in the pocket with a small blunt cannula. A bandage contact lens was applied before the speculum was removed; the bandage contact lens was removed the day after surgery. Operated eyes were not patched. All patients were instructed to instill topical levofloxacin in combination with topical tobramycin-dexamethasone 4 times daily for 1 week, after which they were instructed to taper by 1 drop per week over 4 weeks.

\section{Patient Evaluation}

All patients had an extensive ocular examination (manifest refraction, visual acuity testing, tonometry, pachymetry, keratometry, slitlamp biomicroscopy) including IVCM (Confoscan 4, Nidek Technologies Srl) and AS-OCT (Visante, Carl Zeiss Meditec AG) evaluations. In vivo confocal microscopy was performed by the same examiner (A. C.) in all study eyes before surgery and 1, 6, and 12 months after surgery. One drop of proparacaine $0.5 \%$ solution and artificial tears were instilled immediately before each examination. Patients were asked to look straight ahead, and an in vivo confocal microscope equipped with a standard $40.0 \mathrm{D}$ water-immersion front lens automatically captured images of the full thickness of the central cornea. Each examination took approximately 3 minutes and recorded 350 images at a distance of $1.5 \mu \mathrm{m}$ between successive images on the $z$ axis. Scanning was performed from the epithelium to the endothelium, paying special attention to the stromal interface and inlay edges. The interface was defined as the corneal sublayer in the stroma with evident discontinuity of the stromal keratocyte and extracellular matrix (ECM) architecture. A postoperative ECD was obtained for each eye at every follow-up examination. The center of the cornea was also evaluated and studied at all examinations.

Anterior segment OCT examinations and images of the cornea were taken by the same experienced examiner (A.M.) 1, 6, and 12 months after surgery to assess the morphology, characteristics, and pachymetry of the cornea and pocket. Measurements were repeated 3 times per patient to increase the accuracy of the recorded value. The AS-OCT produced multiple A-scans that formed 2-dimensional images of the cornea using low-coherence interferometry. All images were taken using the "high res corneal" scan option to obtain accurate scans of the corneal structure; a linear transversal scan with the same orientation of the corneal pocket and its orthogonal scan was used in an unaccommodated state and under the same light conditions (50 lux). All patients were asked to look at the optical target in the system. When the corneal reflex (ie, a vertical white line along the center of the cornea) was visible, images were captured. The captured linear scan was rotated 10 degrees clockwise and 10 degrees counterclockwise to identify the image with the best resolution.

After images were obtained, several corneal features were analyzed. The first feature was the angle of the side cut between the edges of the epithelium and the stromal pocket. The second was the seal of the pocket and the resulting regularity of its profile (ie, pocket regularity). The third feature was the difference between the planned and achieved pocket depth, calculated as the distance between the proper interface and the epithelial layer (pocket accuracy); each documented interface depth was the mean of 3 measurements. The final feature analyzed was the interface pocket reflectivity, calculated as the number of light reflectance units visible near the intracorneal inlay. The pachymetry-scan pattern was used to map the cornea; the mean pachymetry of the central $2.0 \mathrm{~mm}$ area was recorded as the CCT for OCT measurements.

\section{RESULTS}

\section{Baseline Characteristics}

The intracorneal inlay was inserted in the nondominant eye of 52 naturally emmetropic presbyopic patients. The mean age of the 36 men and 16 women was 56.1 years (range 46 to 63 years). The mean follow-up after inlay insertion was 7.6 months (range 4 to 12 months). Thirty-six patients $(69.2 \%)$ presented for the 12-month follow-up visit.

Postoperative slitlamp examinations showed clear corneas without evidence of thinning, scarring, or vascularization and well-centered inlays at all timepoints in all eyes (Figure 1). All remaining ocular examinations were normal. Three inlays were explanted before the 6-month visit due to patientreported significant discomfort caused by a reduction in distance vision and the presence of significant halos and glare; 3 additional explantations occurred before the 12-month visit. The mean preoperative CDVA of patients having explantation was $-0.06 \log$ MAR with a mean refractive $\mathrm{SE}$ of $0.16 \mathrm{D}$; the mean postexplantation CDVA was $0.00 \log \mathrm{MAR}$ with a mean refractive SE of 0.23 .

\section{In Vivo Confocal Microscopy}

The epithelium, including the superficial epithelial cells and intermediate and basal cell layers, showed well-described normal structures of healthy corneas in all eyes at all follow-up examinations. The basal 


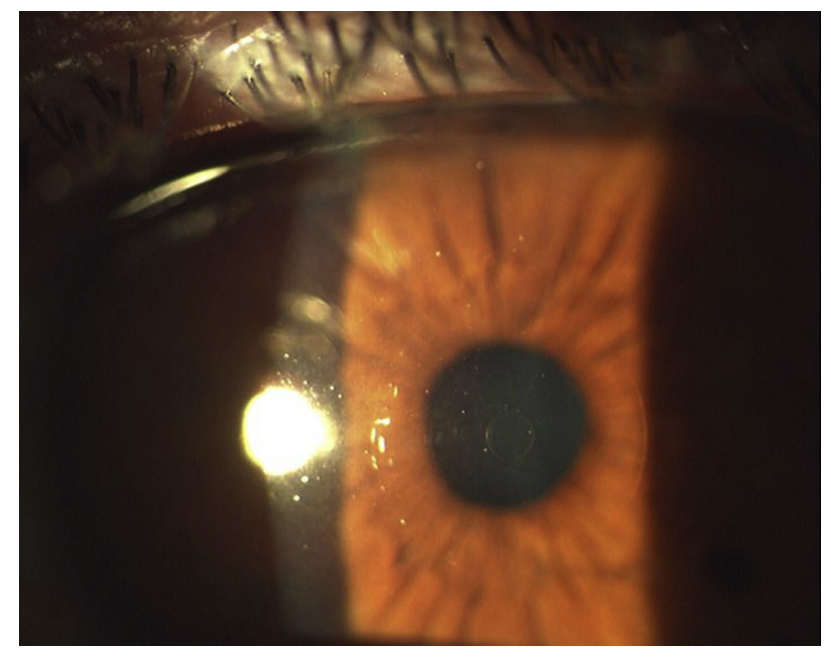

Figure 1. The intracorneal inlay in the eye of a patient 12 months postoperatively.

cells were uniform in size and reflection. The basal epithelial layer images showed hyperreflective dots in several eyes 1 month postoperatively; however, this phenomenon was not present at the 6- or 12-month examination (Figure 2).

Bowman membrane appeared as a nonreflective structure, and the beaded nerve fibers of the subepithelial nerve plexus were the only distinguishable elements. At 1 month, the subbasal nerve plexus images showed a small reduction in the number of nerves with increased tortuosity and reflectivity, which decreased by 6 months postoperatively. Some beadlike formations, defined as highly reflective bulbous portions of the subbasal nerve, were also observed. By 12 months postoperatively, all patients had regained the nerve morphologic features imaged preoperatively (Figure 3).

The anterior stroma under the basal membrane was normal in all eyes, and only slight reflections from the keratocyte nuclei were seen against a darker background. Moreover, in the early postoperative period, these cells were surrounded by hyporeflective irregular areas of mild edema (Figure 4, A, B). At 12 months, the anterior stroma appeared normal with few activated keratocytes (Figure 4, C, D).

At 1 month, many small, bright, round cells of various sizes and a few highly reflective dendriticshaped cells with short branching were visible just near the treated stroma in all eyes (Figure 5, A). Many bright oval or round microdots were clearly visible in the anterior and intermediate stroma, and increased deposition of what appeared to be abnormal ECM was observed in the anterior stroma near the intracorneal inlay (Figure 5, B). Diffuse deposits of dystrophic material interspersed between the keratocyte nuclei were found in the intermediate stroma. The keratocytes of the mild stroma were more activated, and a large zone of what appeared to be apoptotic keratocytes was found on the anterior surface of the corneal inlay (Figure 5, C). Hyperreflective areas and an irregular amorphous structure or pattern were seen on the anterior surface of the intracorneal inlay near the interface of the pocket in all eyes.

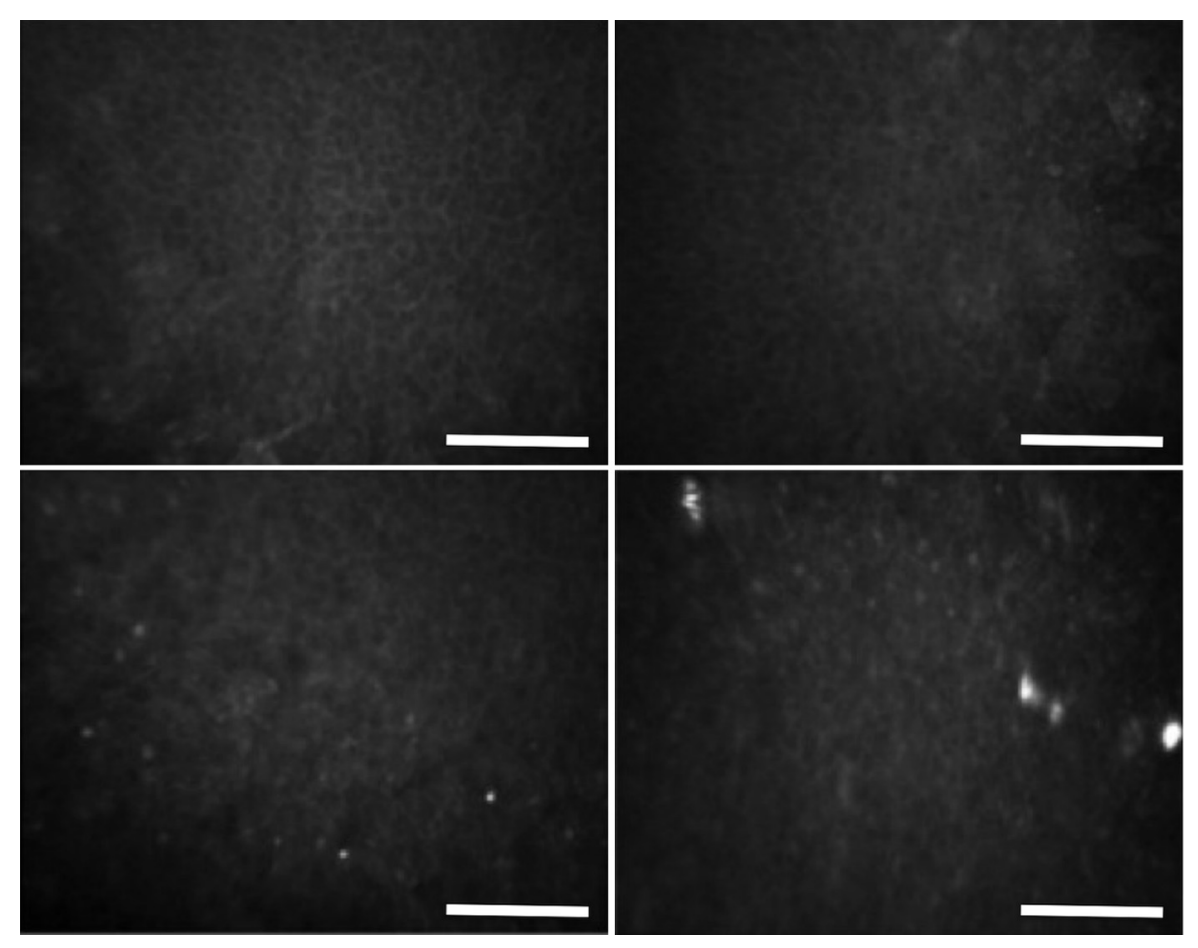

Figure 2. In vivo confocal microscopy. The epithelium appears normal with some hyperreflective dots in the basal epithelial layer. The dots disappeared by 6 months postoperatively (scale $=100 \mu \mathrm{m}$ ). 


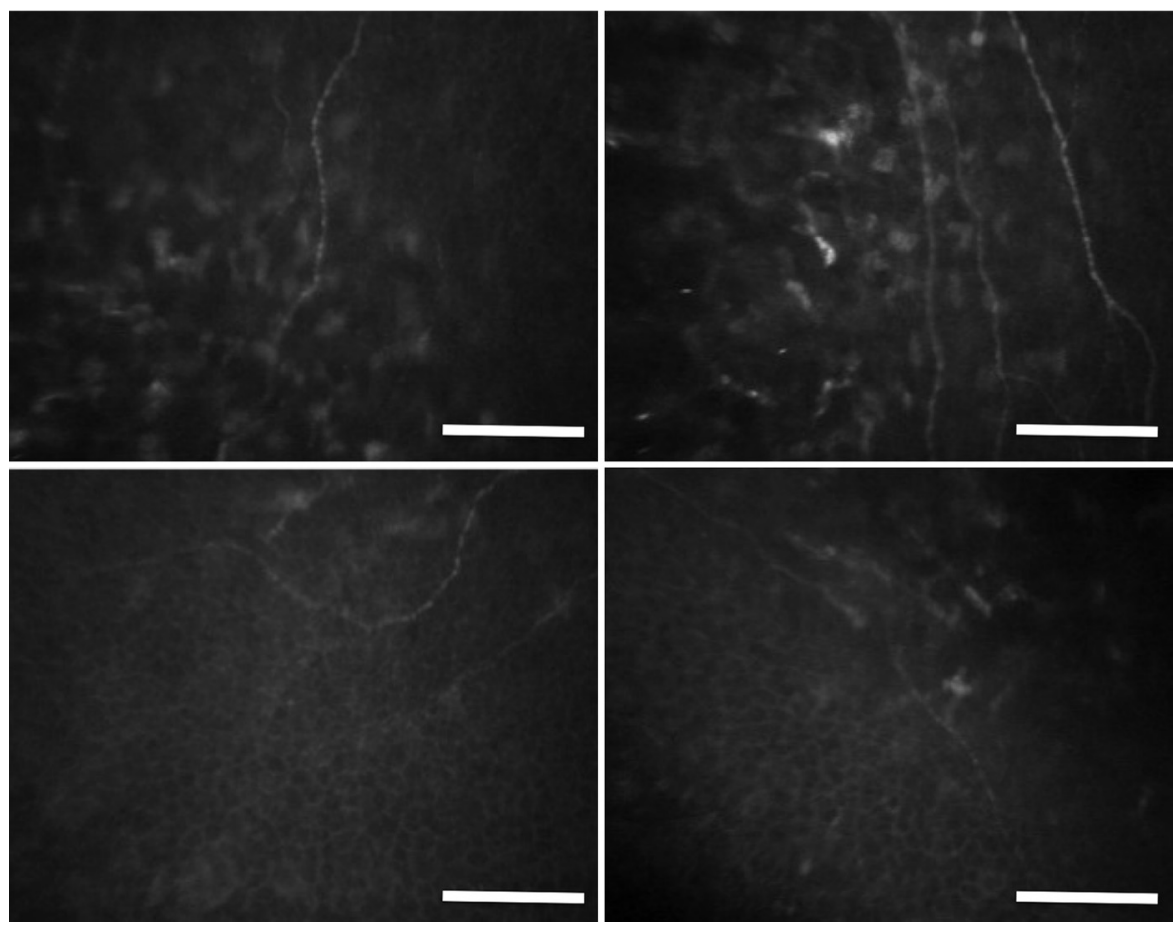

Figure 3. In vivo confocal microscopy shows a small reduction in the number of nerves with increased tortuosity and reflectivity and beadlike formations at 1 month in the subepithelial nerve plexus; regular nervous morphologic features were observed 12 months postoperatively $($ scale $=100 \mu \mathrm{m})$

Multiple variable hyporeflective areas indicating isolated stromal edema were also surrounded by these hyperreflective structures (Figure 5, D). At 6 months, 24 of 47 eyes had hyperreflective cells, indicating possible fibroblastic activity and small, insignificant isolated haze in the intermediate stroma (Figure 6, A, $B)$. After 12 months, a few hyperreflective keratocyte nuclei were visible above a slight hyperreflective background, indicating the anterior surface of the inlay (Figure 6, C, D).

The edge of the corneal inlay with its central hole was clearly seen (Figure 7). The posterior corneal stroma was normal in all eyes. Hyporeflective perpendicular lines of microstriae were observed in a few
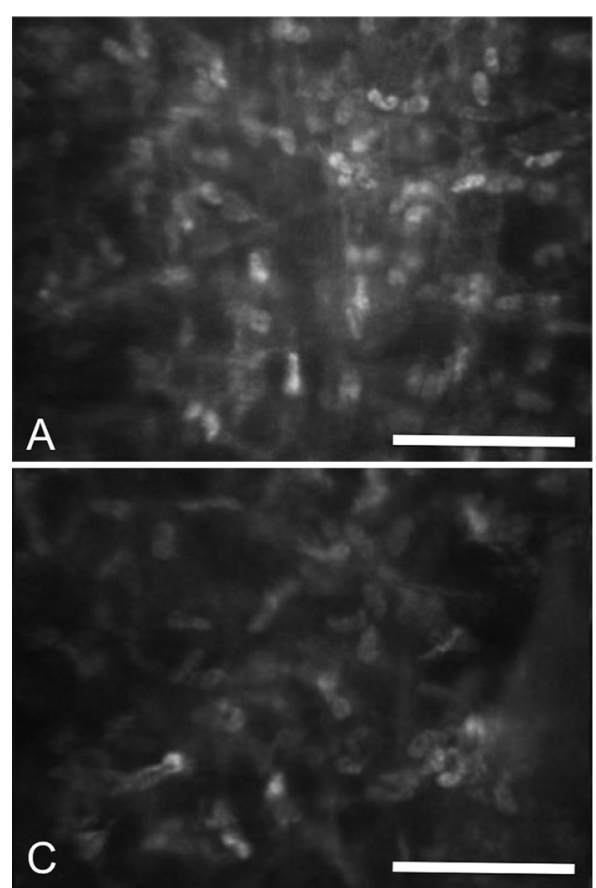
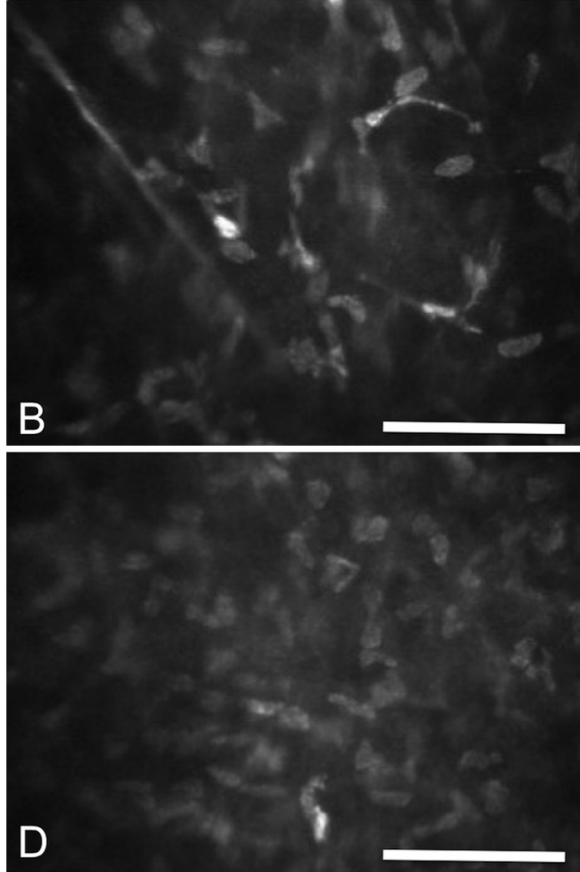

Figure 4. In vivo confocal microscopy. A and $B$ : Keratocytes surrounded by hyporeflective irregular areas of mild edema were seen in the anterior stroma 1 month postoperatively. $C$ and $D$ : The anterior stroma appeared normal with few activated keratocytes at 12 months (scale $=100 \mu \mathrm{m})$. 


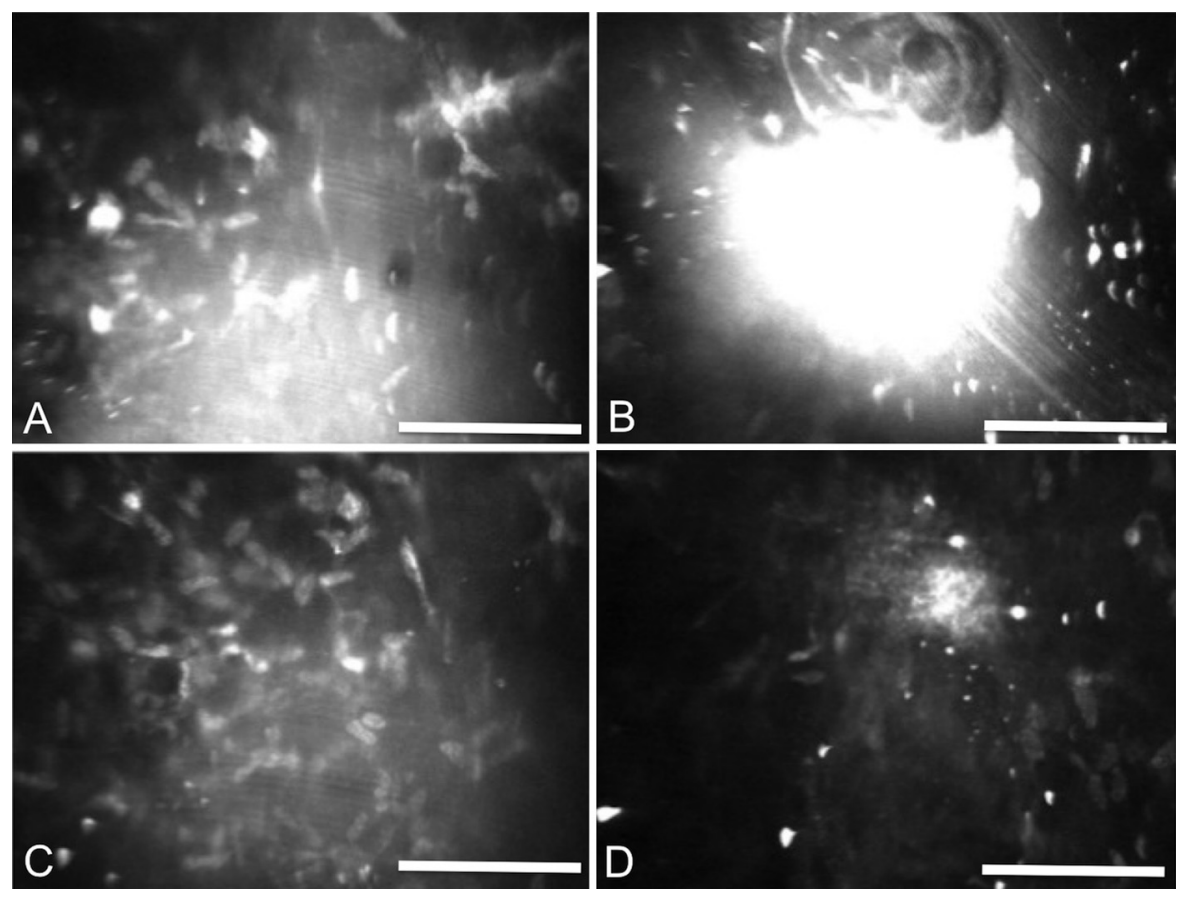

Figure 5. In vivo confocal microscopy. A: Small, bright, round and highly reflective dendritic-shaped cells with short branching. B: Bright oval or round microdots and deposition of abnormal ECM are visible in the area near the treated stroma. C: Activated keratocytes with dystrophic material at the level of the mid stroma were seen. D: Hyperreflective areas and irregular amorphous structure surrounded by isolated stromal edema on the anterior surface of the corneal inlay (scale $=100 \mu \mathrm{m})$.

patients in the early postoperative visits; however, they decreased by the 12-month postoperative visit (Figure 8, A, B). The endothelial cells on the endothelium directly beneath the intracorneal inlay appeared to be of regular size and structure (polymorphism and polymegathism) at all follow-up visits (Figure 8, $C, D)$. The mean ECD was 2401 cells $/ \mathrm{mm}^{2} \pm 218$ (SD) preoperatively, $2378 \pm 282$ cells $/ \mathrm{mm}^{2}$ at 1 month, and $2439 \pm 297$ cells $/ \mathrm{mm}^{2}$ at 12 months; there were no statistically or clinically significant changes in ECD during the postoperative follow-up.

\section{Anterior Segment Optical Coherence Tomography}

The AS-OCT device provided images of the entire cornea, pocket, and intracorneal inlay section of the
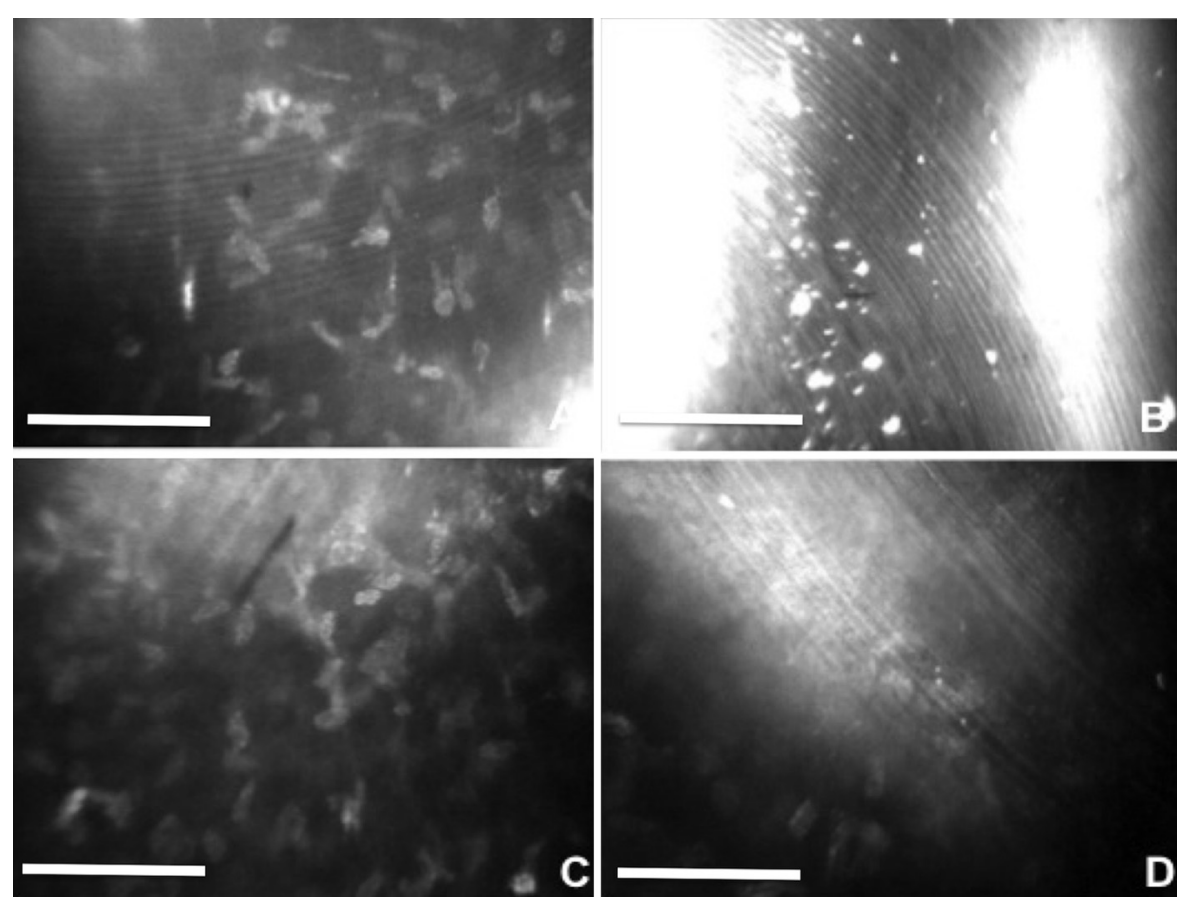

Figure 6. In vivo confocal microscopy. A and $B$ : At 6 months, fibroblastic activity and small isolated haze were seen in the intermediate stroma. $C$ and $D$ : After 12 months, few hyperreflective keratocyte nuclei were visualized through the lens above a slight hyperreflective background (scale $=100 \mu \mathrm{m})$. 


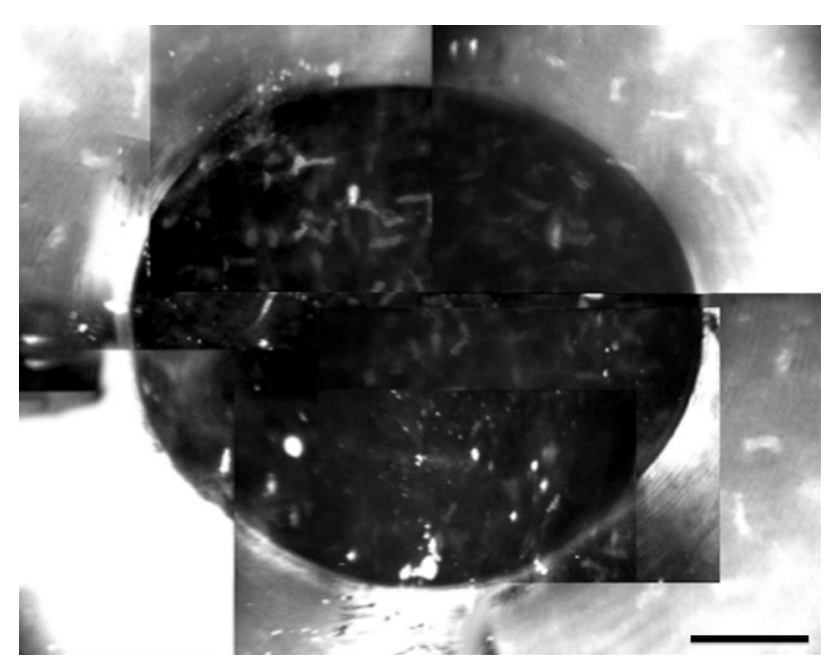

Figure 7. In vivo confocal microscopy (reconstruction of image) shows the edge of the intracorneal inlay with its central hole (scale $=100 \mu \mathrm{m}$ ).

eyes. The side-cut angle of the pocket showed that the incision quality was excellent in all eyes. The mean value of the angles, trigonometrically calculated using OCT measurement parameters, was $30.7 \pm 0.5$ degrees. There was no evidence of epithelial gape or misalignment (Figure 9). The morphology of the flap and pocket showed a regular planar shape in all eyes (Figure 10, A). The pocket was visible as a hyporeflective meniscus in the center of the cornea with gradually increased linear reflectivity toward the periphery. The mean combined value of the central pocket depth and the intracorneal inlay interface was $292.14 \pm 10.75 \mu \mathrm{m}$ at 1 month and
$290.23 \pm 9.51 \mu \mathrm{m}$ at 12 months (Figure 10, B). The mean difference between the measured pocket depth and the planned pocket depth was $7.86 \mu \mathrm{m}$ and $9.77 \mu \mathrm{m}$ at 1 month and 12 months, respectively. The mean interface depth remained stable without significant variations during the entire follow-up.

At 1 month, the AS-OCT examination showed slight diffuse edema in all eyes. There were some hyperreflective areas beneath the intracorneal inlay, representing the femtosecond laser-treated area (Figure 11, A). Microfolds were observed in some eyes at the level of the interface (Figure 11, B). After 12 months, a regular anterior segment profile was seen with complete recovery of the central and peripheral stroma and a reduction in hyperreflective areas (Figure 11, C).

Interface pocket reflectivity, defined as the number of high reflectivity areas identified, was calculated (Figure 11, D). Twenty-one $(40.3 \%)$ of 52 eyes at 1 month and $19(52.8 \%)$ of 36 eyes at 12 months showed more than 3 visible light-reflectance units near the intracorneal inlay. The significance of these reflective areas was unknown, and the number of reflectance units diminished during the postoperative follow-up. The mean CCT was $568 \pm 37 \mu \mathrm{m}$ preoperatively, 559 $\pm 41 \mu \mathrm{m}$ at 1 month, $558 \pm 39 \mu \mathrm{m}$ at 6 months, and $551 \pm 47 \mu \mathrm{m}$ at 12 months.

\section{In Vivo Confocal Microscopy and Anterior Segment Optical Coherence Tomography After Inlay Removal}

Three of 6 patients who had inlay explantation were followed for an additional 6 months after explantation
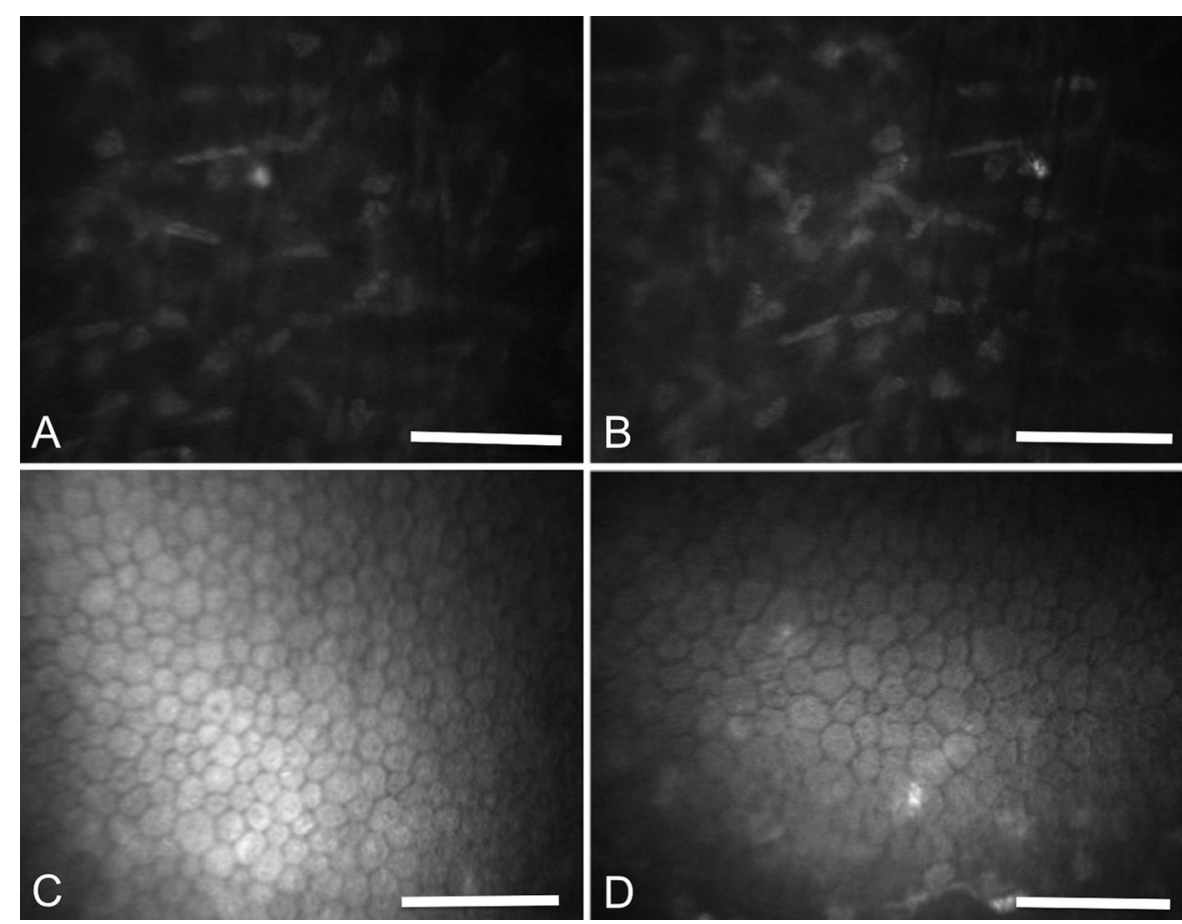

Figure 8. In vivo confocal microscopy. A: Hyporeflective perpendicular lines visualized as microstriae in the posterior corneal stroma B: Reduction was seen 12 months postoperatively. $C$ and $D$ : Endothelial cells are regular in size and structure (scale $=$ $100 \mu \mathrm{m})$. 


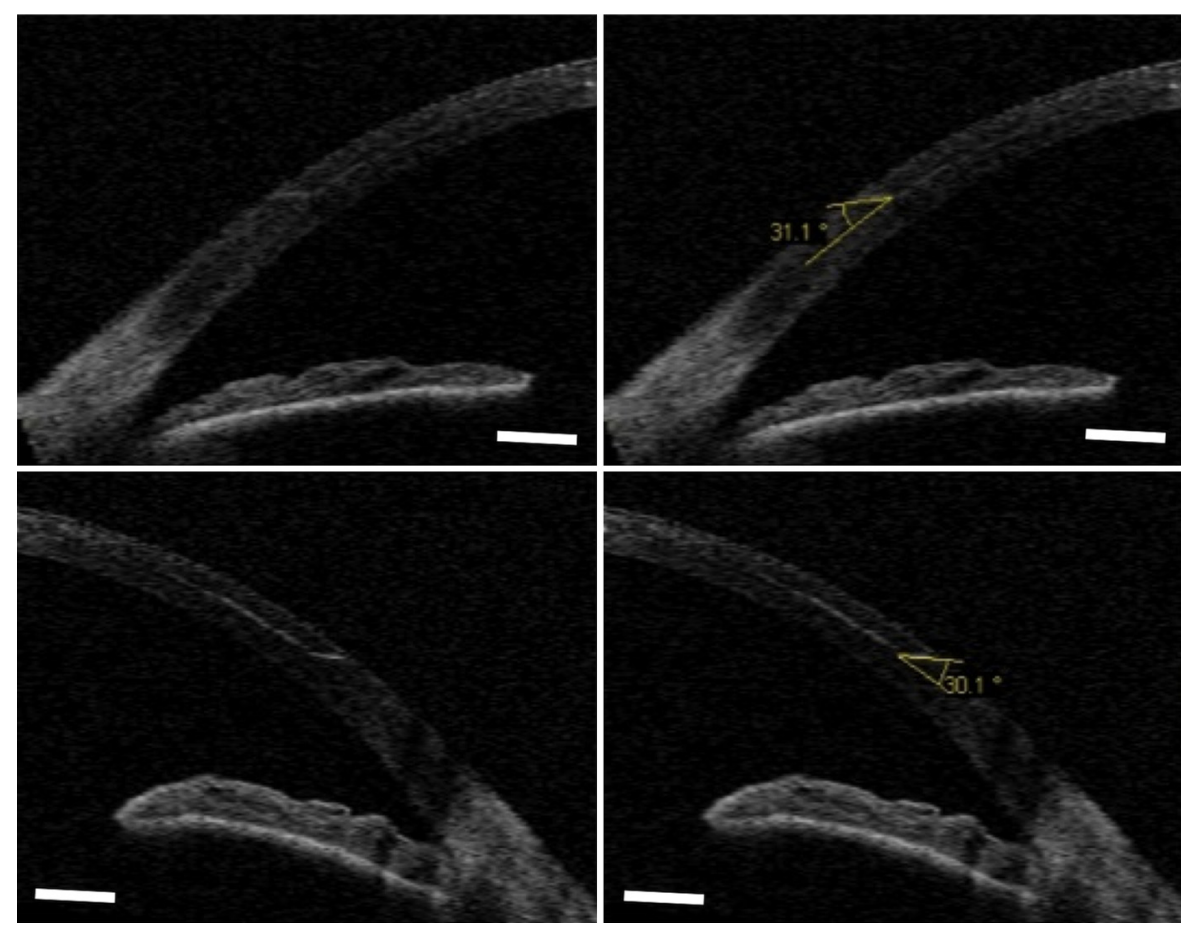

Figure 9. Anterior segment OCT shows the side-cut angle of the pocket. Note the absence of epithelial gape and misalignment $($ scale $=500 \mu \mathrm{m})$. and were examined with IVCM and AS-OCT 6 months after inlay removal. Ocular biomicroscopy showed clear corneas without pocket alterations or signs of irregularity in all 3 eyes. Under IVCM, slight fibrosis was visible in the intermediate stromal section near the pocket in which the inlay had been implanted (Figure 12, A); a few highly reflective microdots were detectable (Figure 12, B). The endothelium appeared healthy without signs of polymorphism in all 3 eyes. Anterior segment OCT cross-sectional images of the cornea showed uniform corneas in all eyes without a change in shape or epithelial surface irregularities.
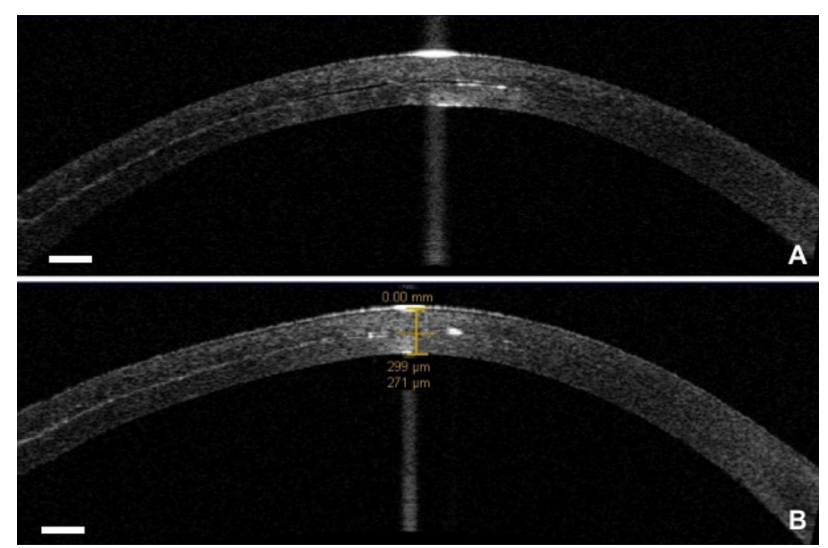

Figure 10. Anterior segment OCT. A: Regular planar shape of the flap is seen. The pocket is of a hyporeflective meniscus shape with gradual increased reflectivity toward the periphery. $B$ : Evaluation of the central pocket thickness and the inlay interface (scale $=$ $500 \mu \mathrm{m})$.
The stromal pocket was not easily detectable, even when it was possible to visualize it in the early postoperative period. In some sections, a discontinuous hyperreflective line (Figure 12, C) was visible 6 months after inlay explantation (Figure 12, D).

\section{DISCUSSION}

The concept of an intracorneal implant for the correction of presbyopia has a long history. In 1964, Barraquer $^{12}$ used flint glass; however, anterior stromal necrosis occurred followed by extrusion of the implant. Implantation of several corneal inlays of different materials using different surgical techniques, including depth of implantation, have been described in the literature; however, many complications were associated with implantation of earlier designs. Complications included corneal stroma opacity, haze, deposits, infiltration, corneal necrosis, and inadequate nutrition flow between the anterior and posterior layers of the cornea. ${ }^{13,14}$

Recently, the interest in intracorneal implants has resurfaced, driven by advances in biosynthetic materials and microkeratome and femtosecond laser technology. At present, the Flexivue Microlens is among the newest generation of intracorneal inlays. This inlay is designed to treat presbyopia by its unilateral implantation in the nondominant eye.

To our knowledge, this series is the first to report the outcomes of IVCM and AS-OCT examinations of corneal features in eyes with a Flexivue Microlens. We believe this is because the procedure is relatively new 

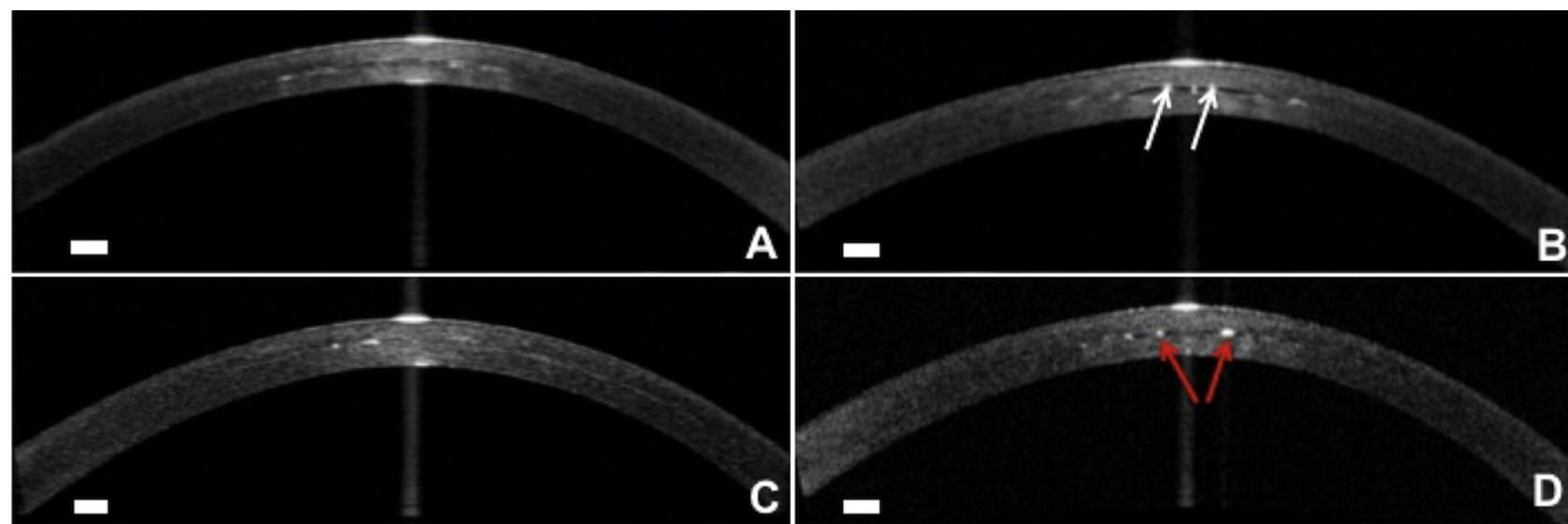

Figure 11. Anterior segment OCT. A: Area of eye that had femtosecond laser pocket creation. Hyperreflective areas are seen beneath the inlay. $B$ : Microfolds on the interface (white arrows). C: After 12 months, reduction of hyperreflective areas was observed. D: High reflectivity areas in the interface (red arrows) (scale $=500 \mu \mathrm{m})$.

and the cellular response of the cornea to the inlay has not been fully characterized. The outcomes in our series showed that the corneal tissue in eyes tolerated the presence of the inlay without difficulty; however, some issues were encountered that require consideration.

There are always concerns regarding placement of a synthetic material in the cornea. The ideal synthetic material should be permeable enough to allow adequate nutrient flow through the cornea because virtually all corneal nutrients come from the aqueous humor. ${ }^{15}$ The material used in the inlay design should also maintain original optical properties after implantation. If an intracorneal implant interrupts the flow of glucose and other nutrients to the corneal tissue located anteriorly to it, progressive melting of the anterior cornea and loss of transparency can result. In a study of corneal tissue integrity, Sweeney et al. ${ }^{16}$ determined that a pore size of $100 \mathrm{~nm}$ (diameter and total area) in the membrane material implanted in feline corneas was better than a pore size of $50 \mathrm{~nm}$ or less in providing long-term nutrient flow to the cornea. Dohlman et al. ${ }^{17}$ recognized the importance of water and nutrient movement across the cornea from the aqueous humor. However, glucose transport decreased significantly as the thickness of the implant increased; to obtain the desired refractive effect, they determined the ideal implant diameter should be between $270 \mathrm{~mm}$ and $340 \mathrm{~mm}$.

Based on the CCT outcomes in our series (ie, no change in CCT), the small hole in the center of the Flexivue Microlens provided sufficient nutritional flow of glucose and other metabolic substances. In addition, lipid or other deposits, such as those seen with other intracorneal implants, including hydrogel intracorneal inlays and intracorneal ring segments, ${ }^{18,19}$ were not observed over the 12-month follow-up.

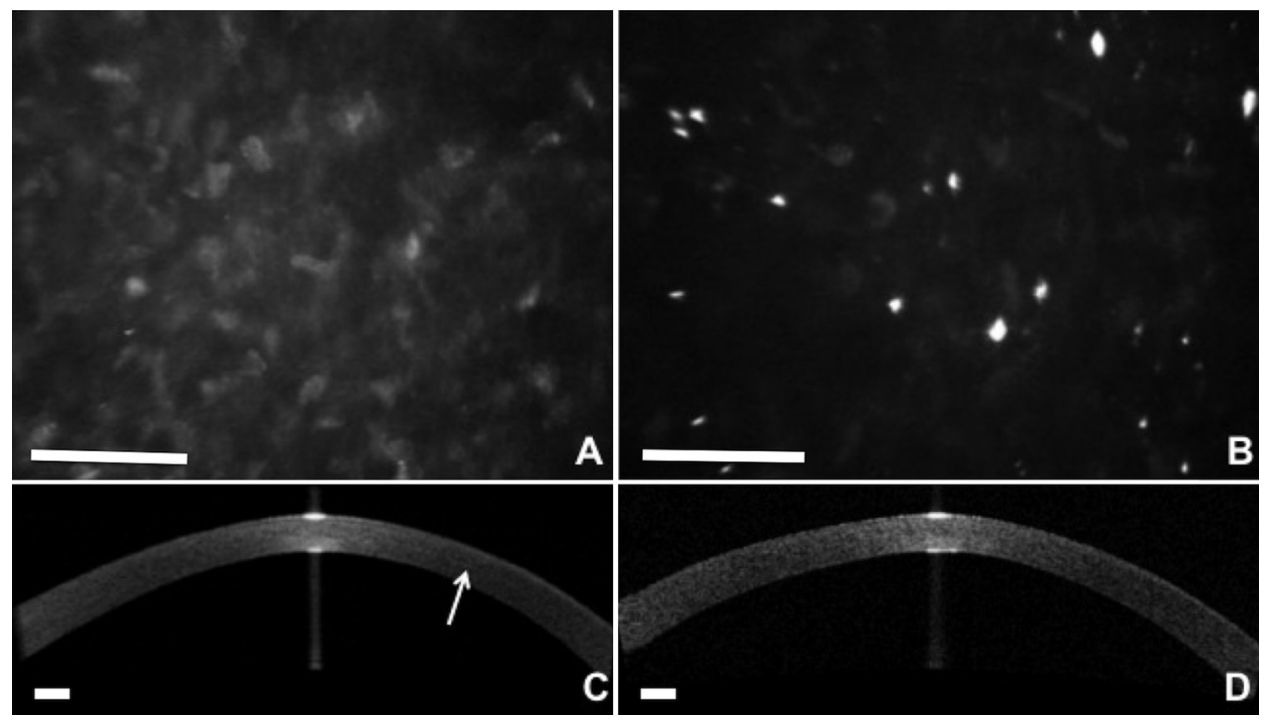

Figure 12. In vivo confocal microscopy. A: Eye of patient after inlay removal with slight fibrosis in the intermediate stromal sections near the pocket. $B$ : Small high reflective microdots also present (scale for $A$ and $B=100 \mu \mathrm{m})$. $C$ : On AS-OCT examination, the stromal pocket is detectable in the early period as a discontinuous hyperreflective line (white arrow). D: Line has disappeared by 12 months (scale for $C$ and $D=500 \mu \mathrm{m})$. 
In a prospective study, Bouzoukis et al. ${ }^{20}$ evaluated the visual outcomes and structural corneal alterations using IVCM after the implantation of the Invue refractive intrastromal inlay (Biovision $\mathrm{AG}$ ) in a corneal pocket created using a mechanical microkeratome. Normal epithelial cells, subepithelial nerve plexus, keratocyte scattering, and endothelial morphology were observed at depths below and above the inlay 12 months postoperatively. In our series, IVCM was used to assess the changes in corneal morphologic features after Flexivue Microlens insertion in all patients and after removal in 6 patients. Our results showed an almost inert response of the corneal tissue to the presence of the inlay. The epithelial layers of the cornea maintained their integrity and were minimally altered by the procedure. In some eyes, the presence of hyperreflective dots could suggest an increase in epithelial activity after the surgical procedure.

The results of the examination of the subepithelial nerve plexus should be considered. During LASIK, the superficial stromal nerves are cut in the flap margin and the nerves in the stromal bed under the flap are subsequently exposed to excimer laser photoablation. ${ }^{21}$ Flap cutting and laser ablation contribute to innervation damage, which develops after LASIK. Post-LASIK corneas, which have undergone significant sensory denervation, tend to present with thicker epithelium; IVCM images showed that the subbasal nerve density decreased 90\% 1 month after LASIK and that the density began to recover by 3 to 6 months. ${ }^{22}$ One important finding in this series is that the pocket approach may minimize the impact on corneal nerves. In fact, IVCM examinations showed no signs of alteration of the subbasal nerve plexus in the eyes. The beadlike formations seen under IVCM were characteristic of metabolically active transmitter-containing nerve fibers. The higher number of beadlike formations and the higher tortuosity were indicative of high metabolic activity, possibly directed toward repairing corneal alterations. ${ }^{23}$

In the early postoperative period, there was some evidence of degenerative cells and cell debris near the inlay in several cases. There are several possible causes for these corneal changes. First, creation of the corneal pocket creates a wound that never fully heals and resolves as a small corneal microscopy modification. Although this is insufficient in itself to interfere with visual outcomes, as seen in post-LASIK surgery cases, incising the cornea results in some direct physical damage to keratocytes. Second, the presence of the inlay in corneal tissue may set up a very subtle, yet continuous response in the stromal keratocytes that persists for as long as the inlay is present. Third, the presence of products of degenerative cell processes, such as lipids around the inlay, combined with the slow accumulation of other surgically related byproducts near the inlay may also be involved. In fact, in the early postoperative period, many hyperreflective microdots were visible as diffuse deposits of dystrophic material interspersed between activated keratocyte nuclei, with a progressive accumulation of abnormal ECM in the stroma near the inlay. These particles may be related to cell degradation products of the ablated corneal tissue, dust or air particles from the operating room, sterile swab remnants, secretory material from the meibomian gland, tear-film debris, a different type of collagen produced in response to the incision, or remains of apoptotic keratocytes. ${ }^{24}$ In a recent study of small particles detected via in vivo confocal microscopy, ${ }^{25}$ the authors correlated ex vivo confocal microscopy with histology and ultrastructural evaluation and suggested that these particles may be small, clear intracytoplasmic vacuoles within keratocytes.

In our series, the inlay surfaces and borders were easily detected on IVCM as hyperreflective areas. In the post-incision tissue reaction immediately after surgery, limited areas of stromal edema were observed as dark areas at the pocket interface. Under IVCM, the eyes had activated hyperreflective keratocytes in places that were in direct contact with the inlay on anterior and posterior surfaces. Extracellular matrix and cellular debris that resulted from the degeneration of keratocytes were also evident around the inlay. Activated keratocytes, presenting as cells with increased nuclear reflectivity in the stroma, were seen when the cellular metabolic activity was increased and were present in the vicinity of the interface at the 1-month follow-up; this activity decreased with time. No inflammatory cells or neovascularization were observed in the vicinity of the inlay after the 12-month follow-up. Keratocytes posterior to the post-interface activation area appeared quiet at all follow-up examinations. The deep corneal stroma in eyes was normal and quiescent; however, early in the postoperative follow-up, perpendicular hyporeflective lines (microstriae) were detected. These microstriae might be the result of interface stretching during the procedures and of transient edema that temporarily compressed the posterior corneal surface, which is more susceptible to deformation. The mean ECD in the surgical eye remained stable.

Identification of the correct lens material and design and determination of appropriate placement within the cornea have presented a challenge to intracorneal inlay manufacturers. Other intracorneal inlay designs have been reported to cause corneal necrosis, epithelial opacification, and problems related to inadequate corneal nutrition. ${ }^{26}$ Deep placement of the inlay in the cornea might be advantageous. In our series, the 
implantation depth of $300 \mu \mathrm{m}$ was selected based on results in a study that determined that deeper stroma has less impact on oxygen and nutrient diffusion in the corneal stroma. ${ }^{27}$ Use of IVCM showed the biocompatibility of the Flexivue Microlens and indicated that it did not alter the cellularity and metabolism of corneal layers in this study. Similarly, AS-OCT allowed us to evaluate the impact of deep placement of the inlay on the corneal architecture. This deep placement creates a thicker "flap" (in this case a corneal pocket) that might minimize the risk for complications and prevent changes in the shape of the anterior cornea. ${ }^{3}$ Another study confirmed that a thicker flap minimizes postoperative flap complications ${ }^{28}$; shallow placement, as seen with Permavision (Anamed) intracorneal implantation, induced epithelial thinning, keratocyte loss, and keratocyte activation when flaps between $110 \mu \mathrm{m}$ and $180 \mu \mathrm{m}$ were used. ${ }^{29}$ In our study, corneal pockets were between $280 \mu \mathrm{m}$ and $300 \mu \mathrm{m}$, which is thicker than the $170 \mu \mathrm{m}$ used in previous studies; no melting, stromal thinning, or other flap-related complications were reported. The change in the mean CCT from preoperatively to postoperatively was not significant, providing further evidence that the inlay did not alter the overall structure of the cornea.

Another study ${ }^{30}$ found that AS-OCT monitoring was useful in evaluating the profile of side cuts and the precise depth of corneal pockets immediately after surgery and in the late postoperative period. In our series, AS-OCT showed that the angle of side cuts and overall incision quality were excellent; the angles of all side cuts were in the range required to obtain secure corneal incisions, providing enhanced wound stability and resulting in regularity of the corneal stromal pockets. The location of the pocket interface and inlay were visible in the eyes due to the reflectivity of interface particles and dark lines in the intermediate stroma. The particles were almost always present but varied in the number and intensity of reflectance. In some cases, the reflection from the interface surfaces was very bright. The source of these reflections was likely cells or extracellular deposits coating the surface of the inlay. The AS-OCT evaluation showed no correlation between pocket-interface reflectivity and particle density.

In this case series, the mean difference between the measured pocket thickness and the planned pocket thickness was very small 1 month and 12 months after surgery, and the mean interface depth remained stable during the postoperative follow-up. Using the $150 \mathrm{kHz}$ femtosecond laser in conjunction with the applanation cone mask created consistent and predictable corneal pockets. In another study, use of the $150 \mathrm{kHz}$ femtosecond laser rather than a microkeratome to create the corneal pocket provided better predictability in pocket surface dimensions (ie, smooth stromal bed creation), a precise target depth (between $280 \mu \mathrm{m}$ and $300 \mu \mathrm{m}$ ), a lower incidence of LASIK-induced dry eye, improved contrast sensitivity, improved visual recovery (as seen in enhanced UDVA results relative to microkeratomes), and improved patient satisfaction. As reported by Zhang et al., ${ }^{32}$ consistency in flap or pocket architecture contributed to better clinical results; as the precision of the flap or pocket increased, the stability of the cornea increased, which resulted in decreased epithelial injury and so forth.

Improved pocket accuracy and regularity using a femtosecond laser of $150 \mathrm{kHz}$ or greater in conjunction with an applanation cone mask are key factors to improve the safety and predictability of this procedure. In our study, the laser parameters for flap creation were modified to obtain smooth stromal beds through use of a mask for pocket creation. This was a key factor that led to a decrease in stromal bed irregularities created by the laser. ${ }^{33}$ In our study, AS-OCT examinations showed small microfolds of the pocket in most eyes; however, the clinical significance of this slight microfolding appeared negligible and may have been a result of stretching of the pocket during surgery or of the inlay's shape and thickness. Based on the design of the Flexivue Microlens, the thickness of the inlay did not alter the interface morphologic features in our patients 1 month after surgery, which is similar to what we see in our patients who have had traditional LASIK.

Additive technologies, such as that provided by the Flexivue Microlens, offer several advantages over currently used refractive surgical techniques. The greatest advantage is that the inlay can be removed; thus, the procedure has the potential of being adjustable. Although there were 6 explantations ( 3 before the 6-month postoperative follow-up; 3 before the 12-month follow-up) during our study, none was related to the biocompatibility of the inlay material or to metabolic compromise of the anterior corneal tissue. Our IVCM and AS-OCT results show that the procedure is reversible and that after inlay removal, there was no significant alteration in the corneal tissue.

In conclusion, considering that the inlay does not require removal of corneal tissue or intraocular surgery and that the procedure is reversible (ie, the inlay can be explanted), the outcomes in our case series show that the Flexivue Microlens was well tolerated for the duration of the 12-month followup. The IVCM analysis showed that the inlay was biocompatible with corneal tissues, eliciting a lowlevel wound-healing response that was confined to 
the stromal tissue in its immediate vicinity. The ASOCT evaluation confirmed no alteration in the corneal structure and shape and that the surgical procedure was repeatable.

\section{WHAT WAS KNOWN}

- Recent advances in femtosecond lasers and material technologies are contributing factors to a renewed interest in intracorneal inlay options to treat presbyopia.

\section{WHAT THIS PAPER ADDS}

- The intracorneal inlay showed excellent biocompatibility with corneal tissue.

- After inlay insertion in the deep stroma, IVCM was useful in evaluating postoperative corneal wound healing and AS-OCT was useful in evaluating the corneal structural features and repeatability of the surgical procedure.

\section{REFERENCES}

1. Alió JL, Chaubard JJ, Caliz A, Sala E, Patel S. Correction of presbyopia by Technovision central multifocal LASIK (presbyLASIK). J Refract Surg 2006; 22:453-460

2. McDonald MB, Hersh PS, Manche EE, Maloney RK, Davidorf J, Sabry M; the Conductive Keratoplasty United States Investigators Group. Conductive keratoplasty for the correction of low to moderate hyperopia: U.S. clinical trial 1-year results on 355 eyes. Ophthalmology 2002; 109:1978-1989; discussion by DD Koch, 1989-1990

3. Yilmaz ÖF, Bayraktar S, Agca A, Yilmaz B, McDonald MB, van de Pol C. Intracorneal inlay for the surgical correction of presbyopia. J Cataract Refract Surg 2008; 34:1921-1927

4. Thomas BC, Fitting A, Auffarth GU, Holzer MP. Femtosecond laser correction of presbyopia (INTRACOR) in emmetropes using a modified pattern. J Refract Surg 2012; 28:872-878

5. Chiou AG-Y, Kaufman SC, Kaufman HE, Beuerman RW. Clinical corneal confocal microscopy. Surv Ophthalmol 2006; 51:482-500

6. Martone G, Alegente M, Balestrazzi A, Nuti E, Traversi C, Pichierri P, Tosi GM. In vivo confocal microscopy in bilateral herpetic keratitis: a case report. Eur J Ophthalmol 2008; 18:; 994-947

7. Jancevski M, Foster CS. Anterior segment optical coherence tomography. Semin Ophthalmol 2010; 25:317-323

8. Maeda N. Optical coherence tomography for corneal diseases. Eye Contact Lens 2010; 36:254-259

9. Dhaliwala JS, Kaufman SC, Chiou AGY. Current applications of clinical confocal microscopy. Curr Opin Ophthalmol 2007; 18:300-307

10. von Jagow B, Kohnen T. Corneal architecture of femtosecond laser and microkeratome flaps imaged by anterior segment optical coherence tomography. J Cataract Refract Surg 2009; 35:35-41

11. Limnopoulou AN, Bouzoukis DI, Kymionis GD, Panagopoulou SI, Plainis S, Pallikaris AI, Feingold V, Pallikaris IG. Visual outcomes and safety of a refractive corneal inlay presbyopia using femtosecond laser. J Refract Surg 2013; 29:12-18
12. Barraquer JI. Conducta de la cornea frente a los cambios de espesor (contribución a la cirugia refractive). Arch Soc Am Oftalmol Optom 1964; 5:81-87

13. Alió JL, Mulet ME, Zapata LF, Vidal MT, De Rojas V, Javaloy J. Intracorneal inlay complicated by intrastromal epithelial opacification. Arch Ophthalmol 2004; 122:1441-1446. Available at: http://archopht.jamanetwork.com/data/Journals/OPHTH/9930/ ECS30149.pdf. Accessed October 29, 2013

14. McDonald MB, McCarey BE, Storie B, Beuerman RW, Salmeron B, van Rij G, Knight PM. Assessment of the longterm corneal response to hydrogel intrastromal lenses implanted in monkey eyes for up to five years. J Cataract Refract Surg 1993; 19:213-222

15. Larrea X, De Courten C, Feingold V, Burger J, Büchler P. Oxygen and glucose distribution after intracorneal lens implantation. Optometry and Vis Sci 2007; 84:1074-1081. Available at: http:// journals.Iww.com/optvissci/Fulltext/2007/12000/Oxygen_and_ Glucose_Distribution_After_Intracorneal.7.aspx\#. Accessed October 29, 2013

16. Sweeney DF, Xie RZ, O'Leary DJ, Vannas A, Odell R, Schindhelm K, Cheng HY, Steele JG, Holden BA. Nutritional requirements of the corneal epithelium and anterior stroma: clinical findings. Invest Ophthalmol Vis Sci 1998; 39:284-291. Available at: http://www.iovs.org/content/39/2/284.full.pdf. Accessed October 29, 2013

17. Dohlman $\mathrm{CH}$, Refojo MF, Rose J. Synthetic polymers in corneal surgery. I. Glyceryl methacrylate. Arch Ophthalmol 1967; 77:252-258

18. Mulet ME, Alio JL, Knorz MC. Hydrogel intracorneal inlays for the correction of hyperopia; outcomes and complications after 5 years of follow-up. Ophthalmology 2009; 116:1455-1460

19. Ruckhofer J, Böhnke M, Alzner E, Grabner G. Confocal microscopy after implantation of intrastromal corneal ring segments. Ophthalmology 2000; 107:2144-2151

20. Bouzoukis DI, Kymionis GD, Panagopoulou SI, Diakonis VF, Pallikaris AI, Limnopoulou AN, Portaliou DM, Pallikaris IG. Visual outcomes and safety of a small diameter intrastromal refractive inlay for the corneal compensation of presbyopia. J Refract Surg 2012; 28:168-173

21. Chen W-L, Shen EP, Hsieh Y-T, Yeh P-T, Wang T-J, Hu F-R. Comparison of in vivo confocal microscopic findings between epi-LASIK procedures with different management of the epithelial flaps. Invest Ophthalmol Vis Sci 2011; 52:36403647. Available at: http://www.iovs.org/content/52/6/3640. full.pdf. Accessed October 28, 2013

22. Kim W-S, Kim J-S. Change in corneal sensitivity following laser in situ keratomileusis. J Cataract Refract Surg 1999; 25:368-373

23. Martone G, Frezzotti P, Tosi GM, Traversi C, Mittica V, Malandrini A, Pichierri P, Balestrazzi A, Motolese PA, Motolese I, Motolese E. An in vivo confocal microscopy analysis of effects of topical antiglaucoma therapy with preservative on corneal innervation and morphology Am J. Ophthalmol 2009; 147:725-735

24. Perez-Gomez I, Efron N. Confocal microscopic evaluation of particles at the corneal flap interface after myopic laser in situ keratomileusis. J Cataract Refract Surg 2003; 29:1373-1377

25. Dawson DG, Holley GP, Geroski DH, Waring GO III, Grossniklaus HE, Edelhauser HF. Ex vivo confocal microscopy of human LASIK corneas with histologic and ultrastructural correlation. Ophthalmology 2005; 112:634-644

26. Waring GO IV, Klyce SD. Corneal inlays for the treatment of presbyopia. Int Ophthalmol Clin 2011; 51(2):51-62

27. Ismail MM. Correction of hyperopia by intracorneal lenses; twoyear follow-up. J Cataract Refract Surg 2006; 32:1657-1660 
28. Li Y, Netto MV, Shekhar R, Krueger RR, Huang D. A longitudinal study of LASIK flap and stromal thickness with high-speed optical coherence tomography. Ophthalmology 2007; 114:1124-1132

29. Lindsey SS, McCulley JP, Cavanagh HD, Verity SM, Bowman RW, Petroll WM. Prospective evaluation of PermaVision intracorneal implants using in vivo confocal microscopy. J Refract Surg 2007; 23:410-413

30. Montés-Micó R, Rodríguez-Galietero A, Alió JL. Femtosecond laser versus mechanical keratome LASIK for myopia. Ophthalmology 2007; 114:62-68

31. Chan A, Ou J, Manche EE. Comparison of the femtosecond laser and mechanical keratome for laser in situ keratomileusis. Arch Ophthalmol 2008; 126:1484-1490. Available at: http:// archopht.jamanetwork.com/data/Journals/OPHTH/6910/ect 80007_1484_1490.pdf. Accessed October 28, 2013

32. Zhang X-X, Zhong X-W, Wu J-S, Wang Z, Yu K-M, Liu Q, Yang B. Corneal flap morphological analysis using anterior segment optical coherence tomography in laser keratomileusis with femtosecond lasers versus mechanical microkeratome. Int J Ophthalmol 2012; 5:69-73. Available at: http://www.ncbi. nIm.nih.gov/pmc/articles/PMC3340831/pdf/ijo-05-01-069.pdf. Accessed October 28, 2013

33. Bouzoukis DI, Kymionis GD, Limnopoulou AN, Kounis GA, Pallikaris IG. Femtosecond laser-assisted corneal pocket creation using a mask for inlay implantation. J Refract Surg $2011 ; 27: 818-820$

\section{OTHER CITED MATERIAL}

A. Chaubard JJ, Castanera J, Pietrini D, Roure A. 6 month European study results of excimer-based treatment of presbyopia using the TECHNOLAS ${ }^{\circledR}$ excimer workstation, March 2011. Available at: http://www.technolaspv.com/dasat/images/0/ 100930-tpv-supracor-white-paper-march-2011.pdf. Accessed October 28, 2013

B. Presbia Coöperatief U.A. Surgeon information, Presbia Flexivue Microlens ${ }^{\mathrm{TM}}$. Available at: http://www.presbia.com/ download/Surgeon\%20Information/LBL-50-030-1-G_Presbia_ surgeon_brochure_email.pdf. Accessed October 28, 2013

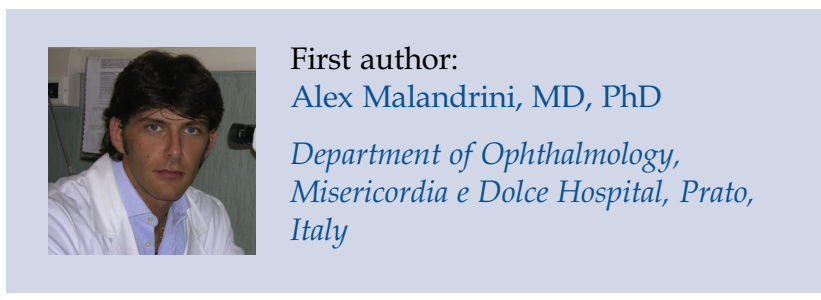

